Research Article

\title{
Characteristics of Valuable Microseismic Events in Heading Face of an Underground Coal Mine Using Microseismic System
}

\author{
Wenlong Zhang $\mathbb{D D}^{1}{ }^{1}$ Tianhong Huo, ${ }^{1}$ Chen Li, ${ }^{1}$ Cunwen Wang, ${ }^{2}$ Xiaocheng Qu, ${ }^{3}$ \\ and Chongwei Xin ${ }^{4}$ \\ ${ }^{1}$ School of Energy and Mining Engineering, China University of Mining and Technology, Beijing 10083, China \\ ${ }^{2}$ Shandong Energy Group Co., Ltd., Jinan 250014, China \\ ${ }^{3}$ Beijing Anke Xingye Technology Co., Ltd., Beijing 100083, China \\ ${ }^{4}$ School of Civil and Resources Engineering, University of Science and Technology, Beijing 100083, China
}

Correspondence should be addressed to Wenlong Zhang; wenlong0523@163.com

Received 31 December 2020; Revised 25 January 2021; Accepted 18 March 2021; Published 27 March 2021

Academic Editor: Marta Berardengo

Copyright (C) 2021 Wenlong Zhang et al. This is an open access article distributed under the Creative Commons Attribution License, which permits unrestricted use, distribution, and reproduction in any medium, provided the original work is properly cited.

Rock burst monitoring of heading face is a weak aspect of rock burst monitoring in China; acoustic emission (AE) monitoring is one of the few monitoring technologies used in heading face, but its target signals are small energy events which are easy to be disturbed. Researchers usually focus on the weak AE events but ignore the microseismic (MS) events (different from AE event and caused by a larger scale of coal fracture), while this kind of events can also reflect the pressure situation of heading face and have higher energy value which may become a better indicator for rock burst monitoring of heading face. So, the basic characteristics of MS events in heading face are studied based on a running vibration signal acquisition system, including the occurrence position, main frequency range, maximum amplitude (MA) range, event duration, and relationship with geological structure. This paper provides a development basis of the monitoring method for rock burst monitoring of heading face by using MS events.

\section{Introduction}

Rock burst is one of the most serious dynamic disasters in underground coal mines of China [1], which may be caused by certain dangerous stress $[2,3]$, specific characteristics of mining coal $[4,5]$, roof strata movement [6], or roadway layout $[7,8]$, and seriously affects the normal operation of coal mine [9]. The key to solve the problem of rock burst lies in clear mechanism [10], effective monitoring [11, 12], and control measures $[13,14]$. Rock burst accident can be divided into working face accident [15] and heading face accident $[16,17]$ according to the different occurrence location. Studies show that $40.74 \%$ occurred in heading face according to the counted 108 accidents of Yima ore district [18]. The monitoring technology of rock burst in working face has been relatively mature now in China $[19,20]$; the whole mine MS system can get the high-energy event caused by breaking of high-level roof [21]; the high-precision MS system can obtain the movement of low-level roof [22]; coal stress monitoring can reflect the change of advanced abutment pressure [23]. However, the rock burst monitoring of heading face is not mature, and the difficulties mainly lie in the following four points: (1) the influence range of excavation is small [24], but the disaster degree is not low [25]; (2) the construction environment is complex, and the construction machineries bring trouble to the effective acquisition [26]; (3) the sensor layout conditions of heading face are limited, which can only be placed in the roadway and cannot spread out; and (4) the excavate speed is fast, about $7 \mathrm{~m}-10 \mathrm{~m}$ every day for comprehensive excavation face and about $20 \mathrm{~m}-30 \mathrm{~m}$ every day for continuous mining face.

Although the monitoring and early warning technologies of heading face are not mature enough, it has also formed some achievements in recent years. The commonly used early warning technologies include AE monitoring [27], coal stress monitoring [28], electromagnetic radiation [29], and conventional pressure monitoring (displacement measurement [30] and bolt force measurement [31, 32]). AE monitoring 
uses $\mathrm{AE}$ events as objects for early warning, and some successful cases have been achieved [33, 34]; however, the energy of $\mathrm{AE}$ events is usually very small and is easy to be interfered by construction equipment or electromagnetic, which may result in inaccurate basic statistics. The change value of stress monitoring is small due to the small influence of heading face, which leads to poor monitoring effect [35]. The operation convenience and anti-interference ability are weak for electromagnetic radiation. The applicability of conventional pressure monitoring to rock burst monitoring is poor and cannot reflect the real dangerous degree of rock burst.

Among the monitoring technologies, it is advantageous to take vibration events as the monitoring and warning index of rock burst [36]. Vibration events can be divided into two types according to different causes, one is caused by roof broken $[37,38]$ and the other is caused by coal body fracture [39]. For working face, two kinds of events all occur, energy and location of roof breaking events can reflect the roof damage situation [40], and quantity and energy of coal fracture event can reflect the situation of advanced abutment pressure [41]. While for heading face, most of the MS events are coal fracture events, the larger the fracture scale is, the greater the energy is [42], and the events can be divided into two categories according to the fracture scale: AE events with small energy, which are caused by a small amount of coal fractures, and MS events with large energy, which are caused by a large scale of coal fractures and usually accompanied by loud sounds [43], but in fact, there is no strict quantitative distinction between $\mathrm{AE}$ events and MS events (at least in the present study, no exact answer has been found). AE events are considered to be related to rock burst risk, which has been verified at many laboratory tests $[44,45]$ and field achievements [46], and the $\mathrm{AE}$ events in the laboratory are completely different from those in the field (the difference between the two may be hundreds of times). MS events in heading face are also related to rock burst risk, and the difference only results in the broken number of coal cells; therefore, the result is that MS events has stronger anti-interference ability compared with AE events. As for the cause of MS event, it is considered that the quantity and energy of MS event may be also related to the advanced abutment pressure ahead of heading face.

As mentioned above, MS event has high research value and may become a new indicator of rock burst monitoring in heading face. So, in this study, the characteristics of MS events are counted and analyzed based on a running vibration signal monitoring system stalled in a heading face of an underground coal mine, and the MS event characteristics include the event location, frequency and amplitude statistics, event duration, and the relationship with geological structure. These characteristics provide a basis for the new idea of using MS events as monitoring and warning objects of heading face.

\section{Engineering Background and Monitoring Materials}

This research relies on a set of online MS system, which is installed in 117 track gateway of Tengdong coal mine, Shandong Province, China. 117 track gateway is excavated along the floor of No. 3 coal seam with buried depth of about $940 \mathrm{~m}$, the average thickness of No. 3 coal seam is $7.37 \mathrm{~m}$, and the rock burst tendency is strong (according to the Chinese standard, the monitoring results of the three monitoring points), and the uniaxial compressive strength of coal seam is about $25 \mathrm{MPa}$. The excavation width and height of 117 track gateway are $4.4 \mathrm{~m}$ and $3.4 \mathrm{~m}$, respectively, and the direct roof is sandstone with an average thickness of $17.94 \mathrm{~m}$ (the bending energy index of roof is $198.65 \mathrm{~kJ}$, as strong rock burst tendency). The construction method is fully mechanized excavation method: excavating machine completes the excavation process, the loader and belt conveyor complete the transportation process, and the bolt and anchor cable drilling rig complete the support process. The excavate speed of 117 track gateway is about $7 \mathrm{~m}$ per day, 18 hours a day for tunneling, and the remaining 6 hours for equipment maintenance. Excavation work was not carried out from July 1 to July 3 due to objective reasons during the statistical period from June 1 to July 9.

The online MS system employed in 117 track gateway consists of one acquisition instrument (stalled underground), four sensors, and one server with corresponding software (on subsurface), as shown in Figure 1. The sensors collect the vibration signals and transmit them to the acquisition instrument, which collects signals of all sensors and transmits them to the ground server for analysis. Parameters of the acquisition instrument are presented in Table 1: the supported max number of channels is 12 and the number of channels used in 117 track gateway is four (each connected to four sensors); the max sampling frequency is $10 \mathrm{kHz}$ and the sampling frequency used in 117 track gateway is $2 \mathrm{kHz}$ (match with the maximum receiving frequency of the sensor); the synchronization time error of each channel is less than $10^{-6} \mathrm{~s}$; the safety level is IP 54 (China standard); the explosion proof grade is Exd I (China standard); it connects to the sensors with two core cables; and the executive standards are GB3836.4-2000 (China standard) and GB/ T24260-2009 (China standard).

Parameters of the sensor are presented in Table 2: the sensor model is GZC60, which is a kind of moving coil speed sensor, the receiving frequency range is $0-800 \mathrm{~Hz}$, the sensitivity is $100 \mathrm{~V} / \mathrm{m} / \mathrm{s}$, the vibration acceleration is $50 \mathrm{~m} / \mathrm{s}^{2}$ (peak acceleration is $500 \mathrm{~m} / \mathrm{s}^{2}$ ), the distortion is less than $0.3 \%$, and the damping coefficient is 0.6 . The four sensors are arranged in a straight line owing to the installation location restrictions of heading face and are installed to the tail of bolt on the roof. The spacing of the four sensors is $50 \mathrm{~m}$, and the order from heading face to back is \#1 sensor, \#4sensor, \#3 sensor, \#2 sensor alternately (described as 1432 to simplify the expression) at June 1st, and the distance between \#1 sensor and heading face is $15 \mathrm{~m}$; when the distance reaches $65 \mathrm{~m}$ with the excavate of heading face, the \#2 sensor shifts to the front and the order changes to \#2 sensor, \#1 sensor, \#4 sensor, and \#3 sensor (described as 2143 to simplify the expression); the shifting rule is shown in Figure 2.

For the waveform of an event, the main parameters include the occurrence position, main frequency distribution, MA distribution, and event duration as shown in Figure 3. The occurrence position refers to the location of the 


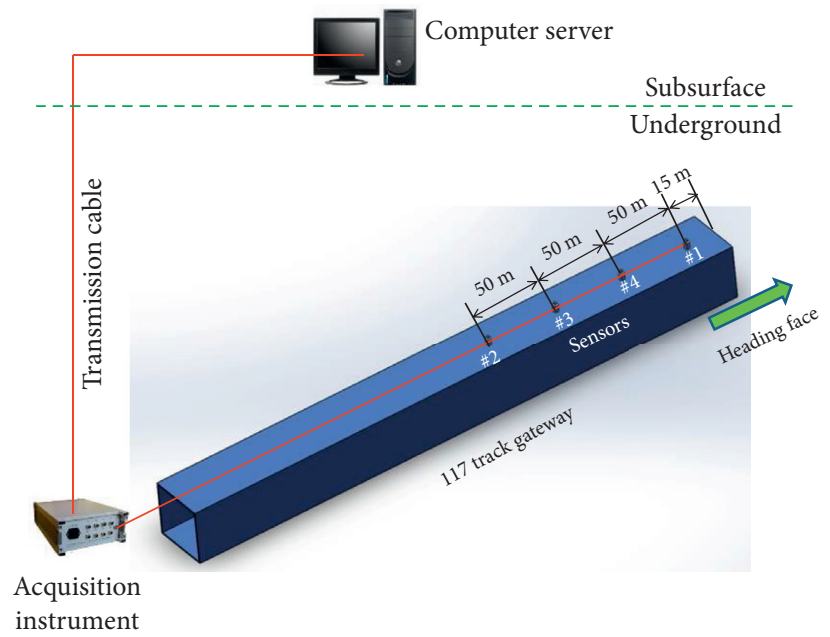

FIgURE 1: MS system installed in 117 track gateway.

TABle 1: Parameters of the acquisition instrument used in the MS system of 117 track gateway.

\begin{tabular}{lc}
\hline Parameter & Parameter description \\
\hline Number of channels supported & Max of 12 (4 used in 117 track gateway) \\
Installation position & Underground \\
Sampling frequency & Max of $10 \mathrm{kHz}(2 \mathrm{kHz}$ used in 117 track gateway) \\
Synchronization time error of each channel & Less than $10^{-6} \mathrm{~s}$ \\
Safety level & IP $54($ China) \\
Explosion proof grade & Exd I (China) \\
Connection mode & Two core cable connection \\
Executive standards & GB3836.4-2000 (China); \\
\hline
\end{tabular}

TABle 2: Parameters of the sensor used in the MS system of 117 track gateway.

\begin{tabular}{lc}
\hline Parameter & Parameter description \\
\hline Sensor model & GZC60 \\
Sensor type & Moving coil speed sensor \\
Receiving frequency & $0-800 \mathrm{~Hz}$ \\
Sensitivity & $100 \mathrm{~V} / \mathrm{m} / \mathrm{s}$ \\
Vibration acceleration & $50 \mathrm{~m} / \mathrm{s}^{2}$ \\
Peak acceleration & $500 \mathrm{~m} / \mathrm{s}^{2}$ \\
Distortion & $\leq 0.3 \%$ \\
Damping coefficient & 0.6 \\
Installation mode & Installed at the end of bolt \\
\hline
\end{tabular}

event (the simplified center of the coal fracture or roof broken), the main frequency refers to the frequency value corresponding to the maximum amplitude value in the spectrum diagram as shown in Figure 3(b), the MA refers to the maximum voltage value caused by the vibration, which represents the strength of the vibration signal, and the event duration refers to the difference between the end time and the arrival time of the event as shown in Figure 3(a). So, the aim of this study is to take statistics and research on the above characteristics of MS events in 117 track gateway, and another discussion point is the factors that related to the occurrence number of MS events.

\section{Results}

With the continuous excavation of heading face, the last sensor moves to the front every time when the distance between the front sensor and the heading face reaches $65 \mathrm{~m}$, and the sensor sequencing from front to back will change after shifting. The sensor sequencing results of four statistical periods during June 1-July 9 are shown in Table 3 . The four periods are, respectively, June 1-June 12, June 13-June 23, June 23-June 30, and July 1-July 9, and the corresponding sensor sequencing results are, respectively, 1432, 2143, 3214, and 4321 , which means that the $2 \#, 3 \#$, and $4 \#$ sensor move forward to the front, respectively, on June 13, June 23, and July 1.

It is very important to determine the occurrence position of the MS event in heading face, and this work has not been studied before, while the vibration signal acquisition system used in this study can complete the preliminary positioning of vibration events. When the MS event occurs, the closer sensor will have a larger amplitude and earlier arrival time theoretically, which is the basic law of signal propagation. Therefore, this study counted the amplitude sequencing and arrival time sequencing results of four channel-triggering events (all four sensors received the MS event) in the statistical period, and the results are shown in Figures 4 and 5. It can be seen from the figure that most of the amplitude 

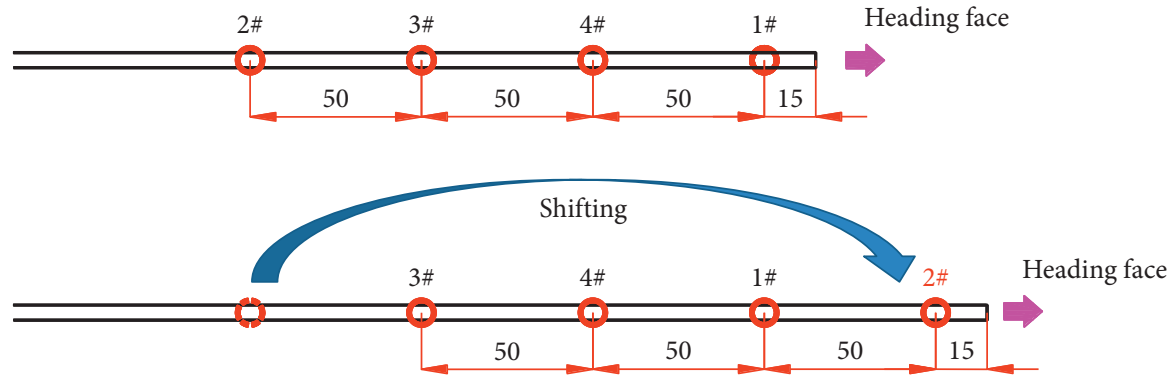

Sensor Unit: $m$

FIgURE 2: Shifting rule of sensor.

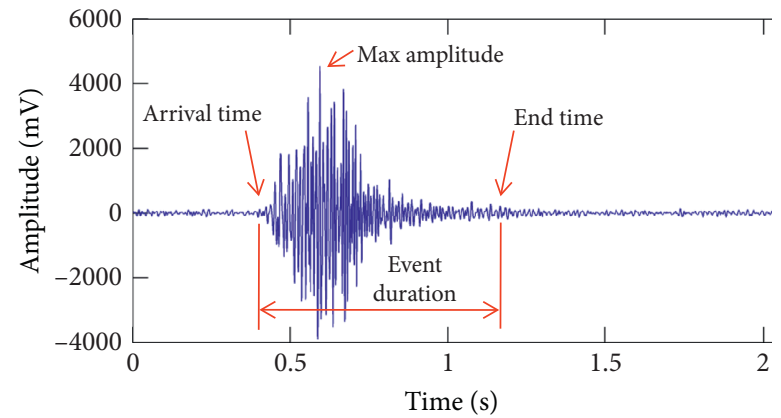

(a)

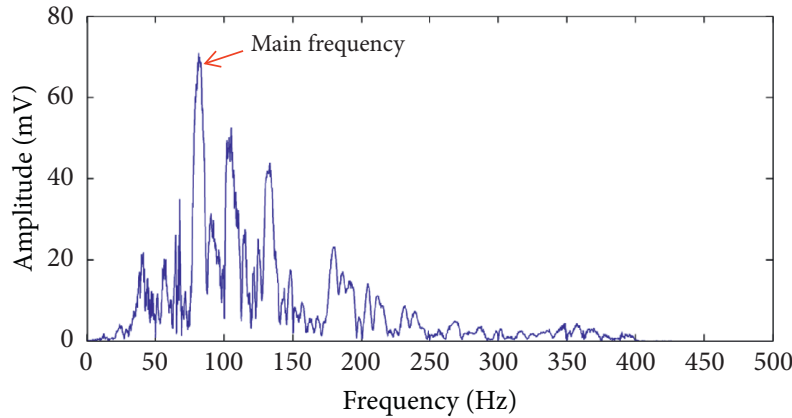

(b)

FIGURE 3: Statistical basic parameters of MS event waveform.

TABLE 3: Sensor sequencing results in different periods.

\begin{tabular}{lcc}
\hline Date & Sensor sequencing (from heading face to back) & Shifting sensor \\
\hline June 1-June 12 & 1432 & - \\
June 13-June 23 & 2143 & $\# 2$ \\
June 23-June 30 & 3214 & $\# 3$ \\
July 1-July 9 & 4321 & $\# 4$ \\
\hline
\end{tabular}

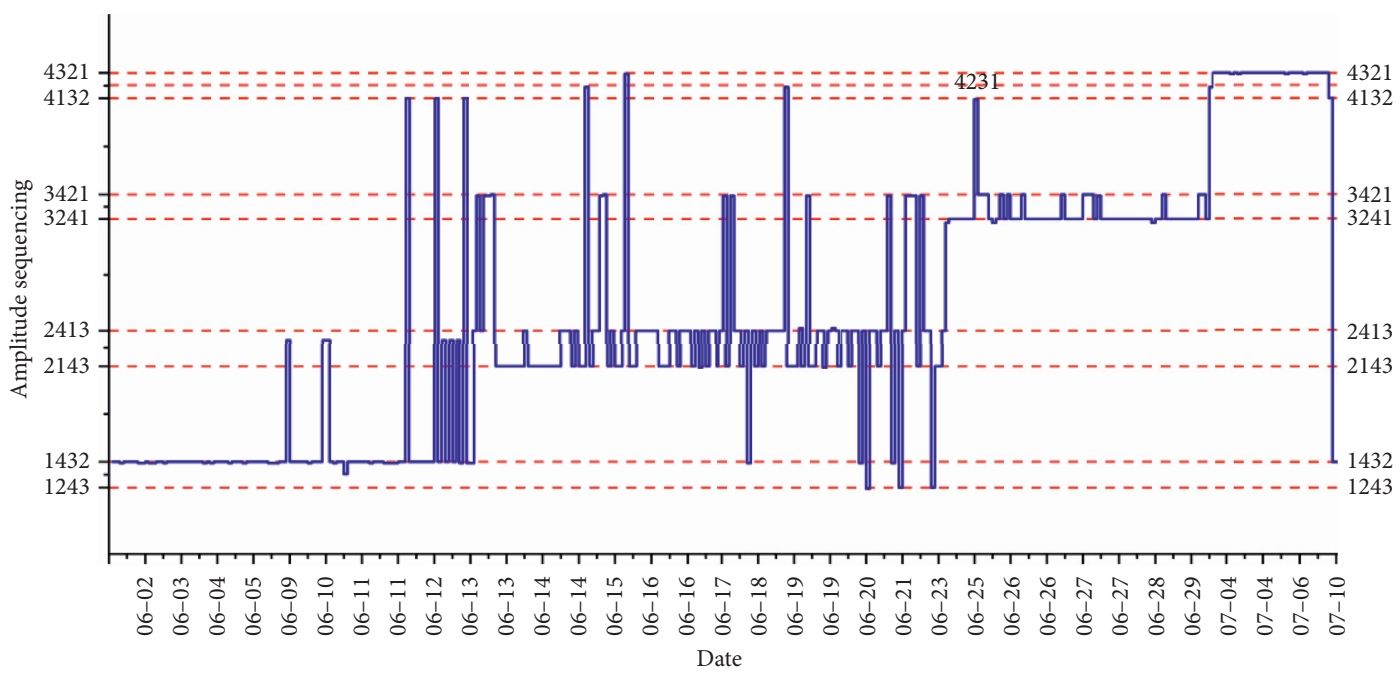

Figure 4: Amplitude sequencing of sensors in statistical period. 


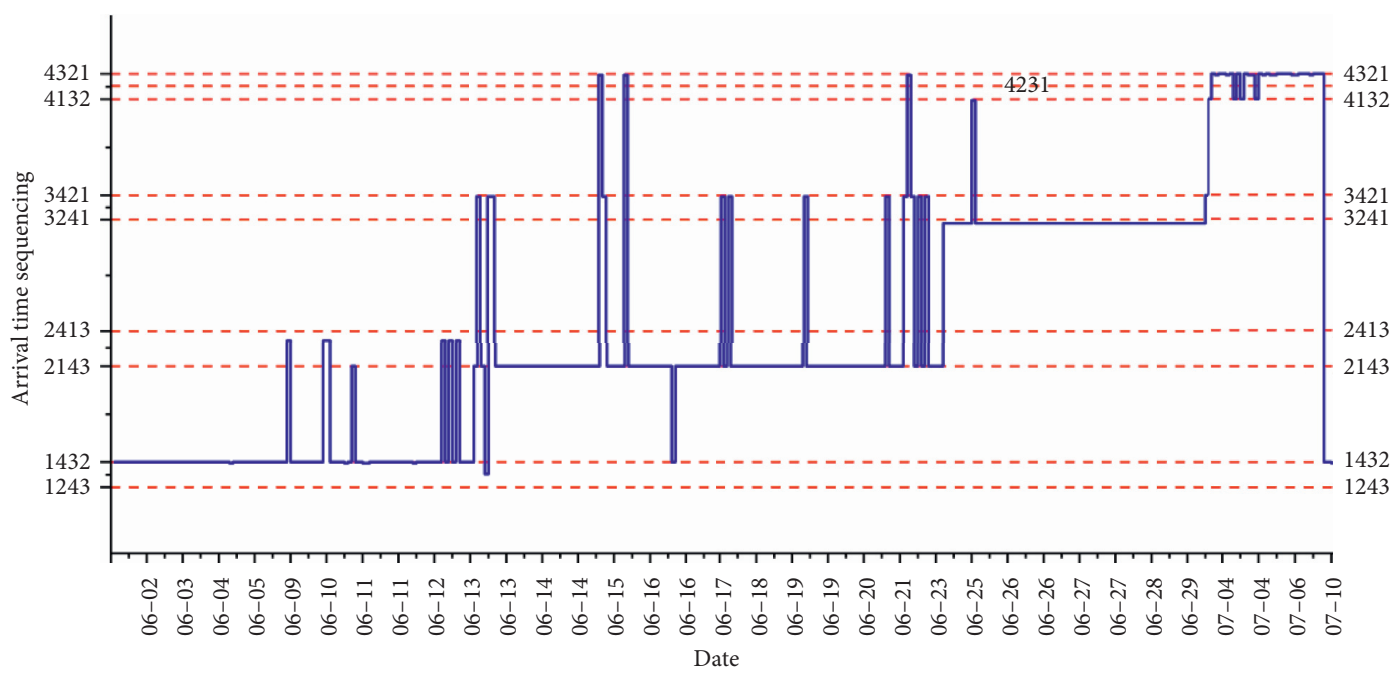

FIgURe 5: Arrival time sequencing of sensors in statistical period.

sequencing and arrival time sequencing are the same as the sensor layout order in the four periods, which indicates that most of the MS events occur in front of the front sensor, and this phenomenon is not affected by the distance between the front sensor and the heading face; therefore, combined with the field sound identification results, the basic conclusion of the study is that most of the MS events occurred near the heading face.

Statistical results of MA and main frequency are shown in Figure 6, and the maximum MA value is about $10000 \mathrm{MV}$ (after checking the waveform, there is no event causing the sensor to exceed the range during the monitoring period), which is lower than MS event in working face. The maximum main frequency is about $500 \mathrm{~Hz}$, which is higher than MS event in working face. There is no absolute relationship between MA value and main frequency value, but when the MA value is larger than $7000 \mathrm{mV}$, the main frequency value becomes relatively low. The box diagram of the distribution range of MA and main frequency values is shown in Figure 7; it can be seen from Figure 7(a) that $25 \%-75 \%$ of MA values are distributed between 799 and $3267 \mathrm{mV}$, and the minimum, average, and maximum values of MA are $295 \mathrm{mV}, 2363 \mathrm{mV}$, and $10258 \mathrm{mV}$, respectively. As can be seen from Figure 7(b), 25\%-75\% of main frequency values are distributed between 82 and $190 \mathrm{~Hz}$, and the minimum, average, and maximum values of the main frequency are $14 \mathrm{~Hz}, 146 \mathrm{~Hz}$, and $515 \mathrm{~Hz}$, respectively.

The duration of the event plays an important role in the expression of the characteristics of MS event, which can reflect the time length of the event, and has a certain significance to reveal the impact time and strength of the vibration on the surrounding rock. The box diagram of event duration is shown in Figure 8; the results show that 25\%$75 \%$ of event duration values are distributed between 0.48 and $0.52 \mathrm{~s}$, which shows a very high degree of concentration; the minimum, average, and maximum values of the event duration are $0.18 \mathrm{~s}, 0.50 \mathrm{~s}$, and $1.78 \mathrm{~s}$, respectively, and obviously, these values are shorter than the MS events in the working face.

\section{Discussion}

The occurrence position, main frequency distribution, MA range, and duration of MS events obtained from the study are of great significance to the research of rock burst mechanism and parameter design of the monitoring system in heading face. Occurrence position determines the layout principle of measuring points of the MS system, the main frequency range determines the sampling frequency of the acquisition instrument and the receiving frequency of the sensor, the maximum value of MA determines the range of the sensor [47], and the duration determines the storage time of a single waveform when the original waveforms are stored.

In the results section, Figures 4 and 5 only qualitatively show that most of the sequencing results of each period are same with the sensor layout order results and the proportion of the matching degree is not specifically counted, so statistical results of the proportion of amplitude sequencing in different periods are stated in Figure 9. It can be seen from the figure that in all of the total 89, 131, 84, 34 MS events occurred, respectively, during June 1-June 12, June 13-June 23 , June 23 -June 30 , and July 1-July 9 , the amplitude sequencing of $85,105,76,28 \mathrm{MS}$ events is the same as the sensor layout order results, and the matching ratio of the four periods is $96 \%, 80 \%, 90 \%$, and $82 \%$, respectively. Statistical results of the proportion of arrival time sequencing in different periods are stated in Figure 10. It can be seen that the arrival time sequencing of $85,111,72,32 \mathrm{MS}$ events is the same as the sensor layout order results for the same total events, and the matching ratio of the four periods is $96 \%, 85 \%, 86 \%$, and $94 \%$, respectively. So, the conclusion is that at least $80 \%$ of the MS events occurred near the heading face according to the sequence results of amplitude and arrival time. In particular, the small number of MS events from July 1 to July 9 was due to the fact that no excavation was carried out from July 1 to July 3.

The correlation coefficient shows the similarity between the changes of two indicators [48]. For the amplitude 


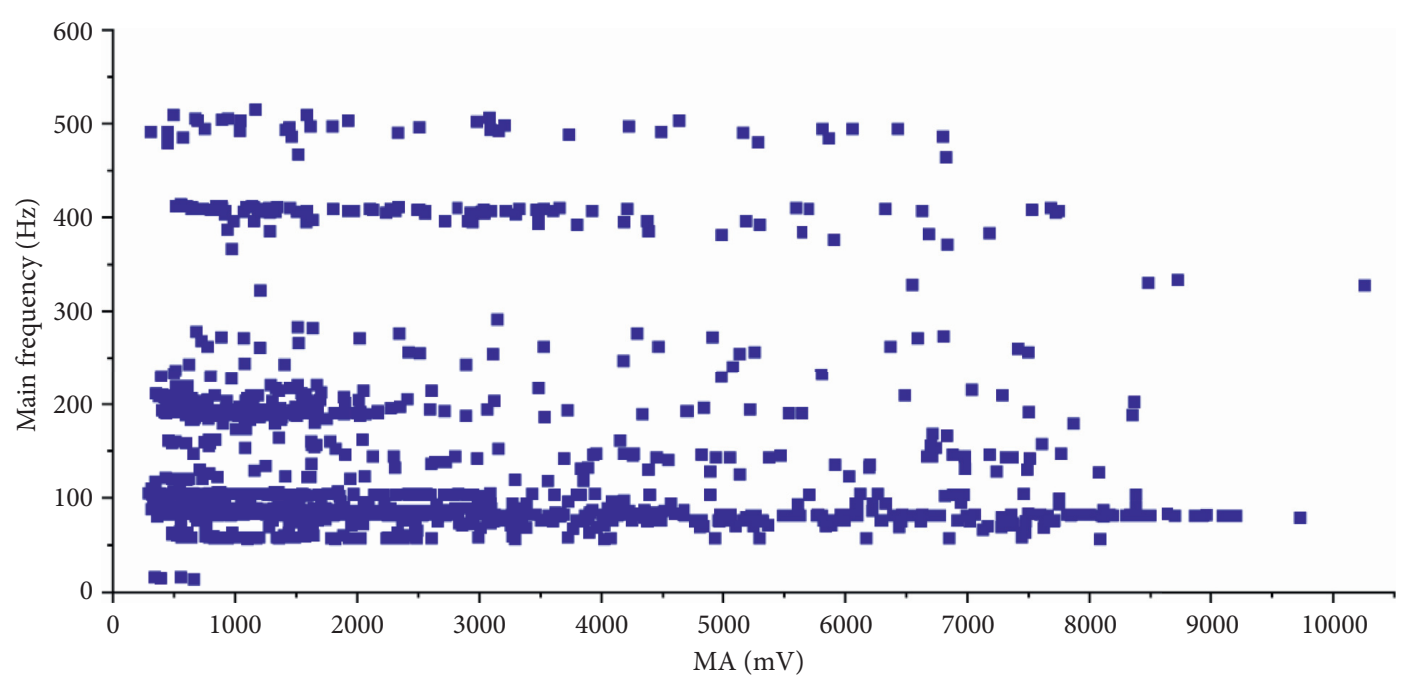

FIgURE 6: Statistical results of MA and main frequency.

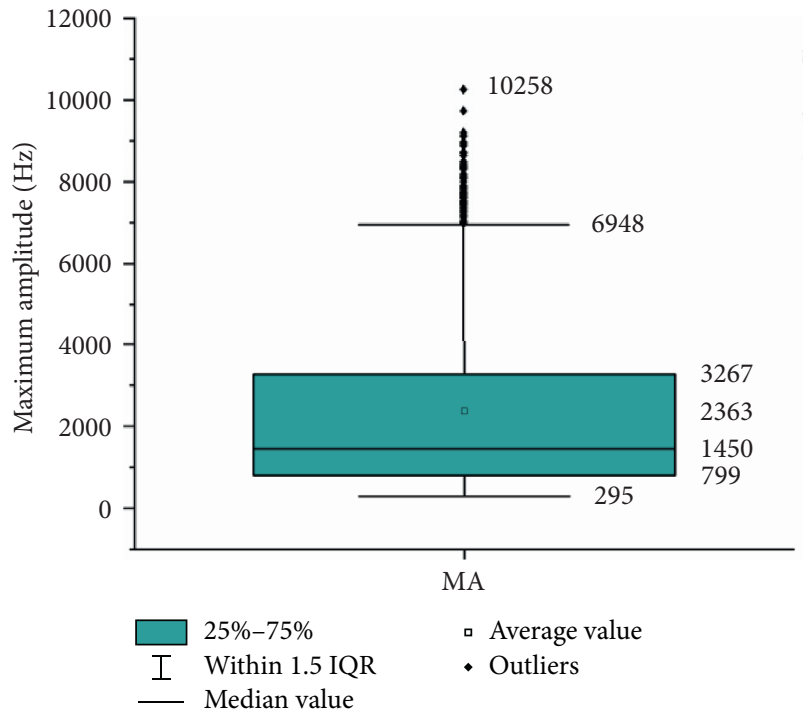

(a)

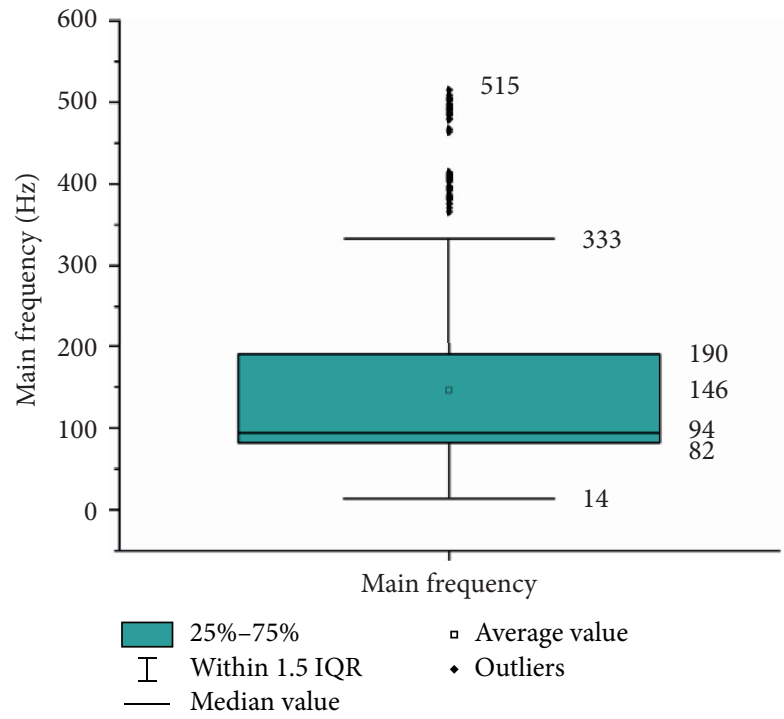

(b)

Figure 7: Box diagram of (a) MA and (b) main frequency.

sequencing and arrival time sequencing results in this study, if the correlation coefficient is large, it indicates that the two sequencing results have a higher degree of conjoint verification of the event position results. Through software calculation, the correlation coefficient of the amplitude sequencing and arrival time sequencing is 0.911 , which proves the conclusion that most of the MS events occur near the heading face.

Another point worth discussing is what factors are related to the occurrence number of MS events. In fact, many studies have shown that the number of MS or AE events is related to the stress level $[49,50]$, and if the stress of coal body is large, there will be more events. The number of MS events represents the change of abutment pressure in front, and the place where the maximum stress adjusted substantially is a certain distance behind the head, which is the accident prone area, while the stress level is quite related to the excavate speed and geological structure, so when the excavate speed changes little, the stress condition is directly related to the geological structure. The original rock stress field at the geological structure must be larger and more complex than that in the normal location. In this study, the occurrence number of three channel-triggering events and four channel-triggering events from June 1 to June 30 is statistically analyzed as shown in Figure 11. The results show that the occurrence number of MS events increases significantly when excavating to the place with small faults, such as June 12 and June 28 in the figure, which shows that the quantity change of MS events in heading face is closely related to the abnormal stress field of geological structure. 


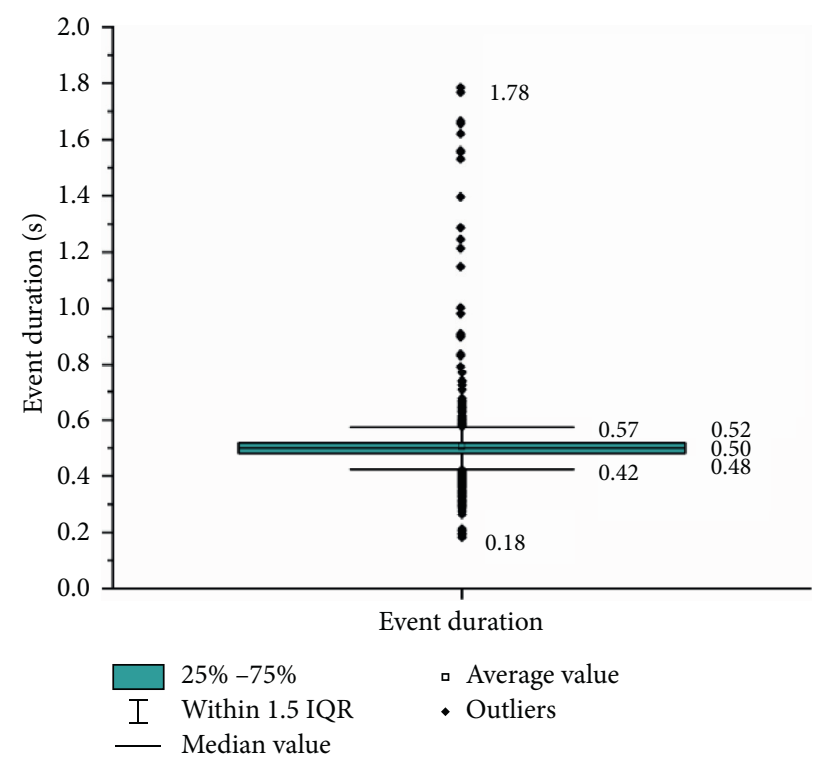

FIgURE 8: Box diagram of event duration.
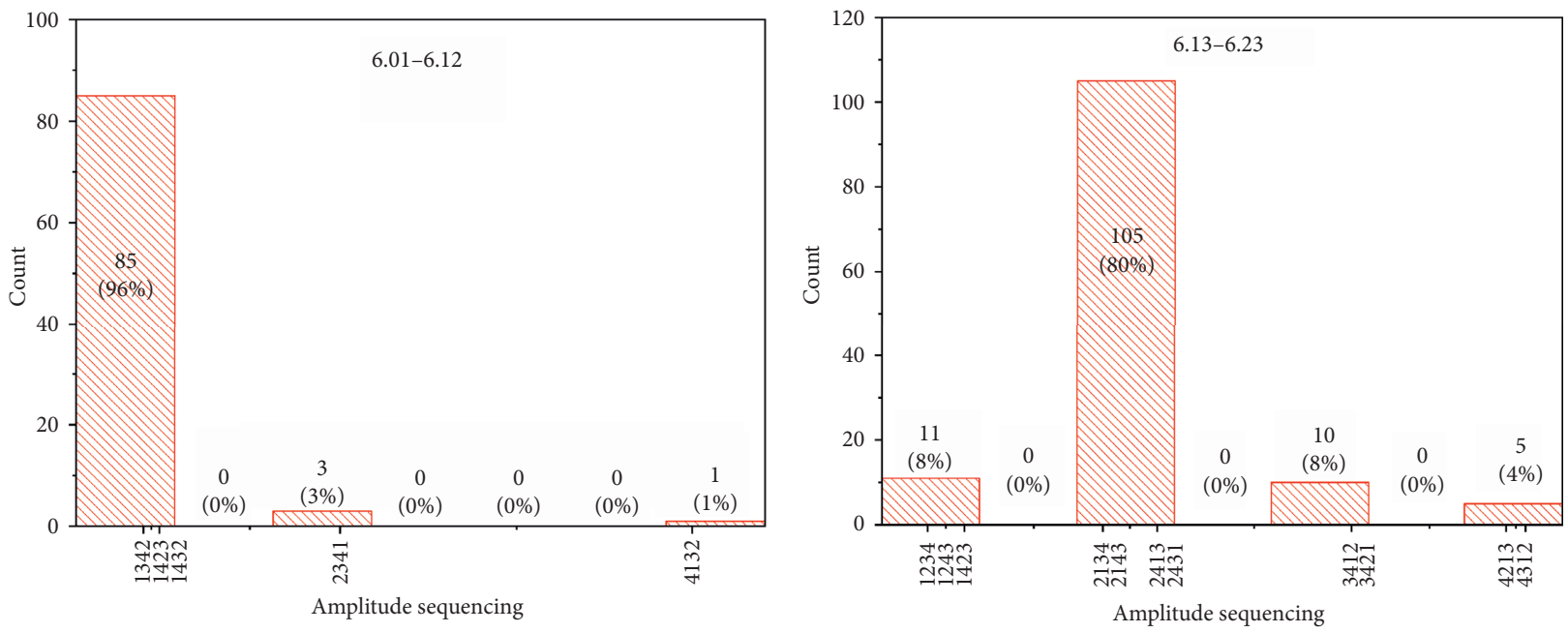

(a)

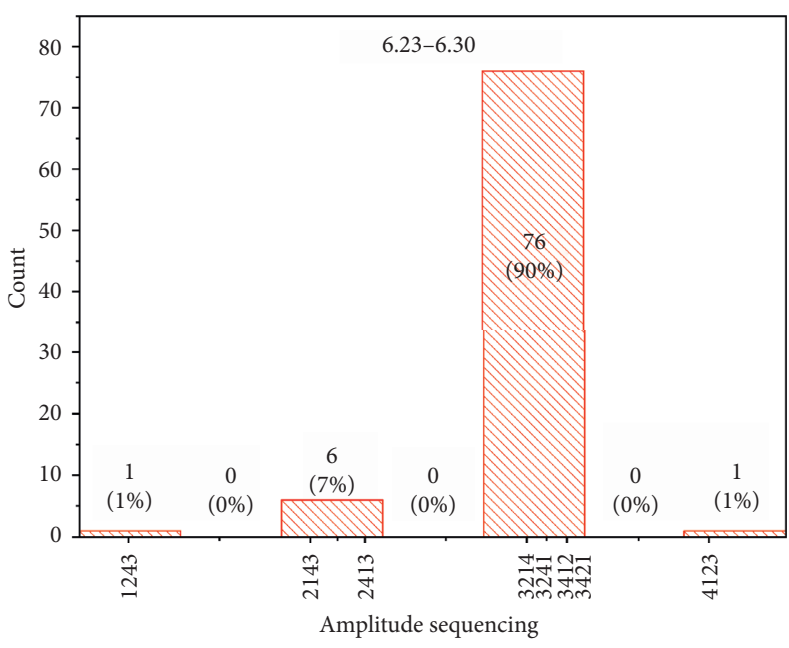

(c)

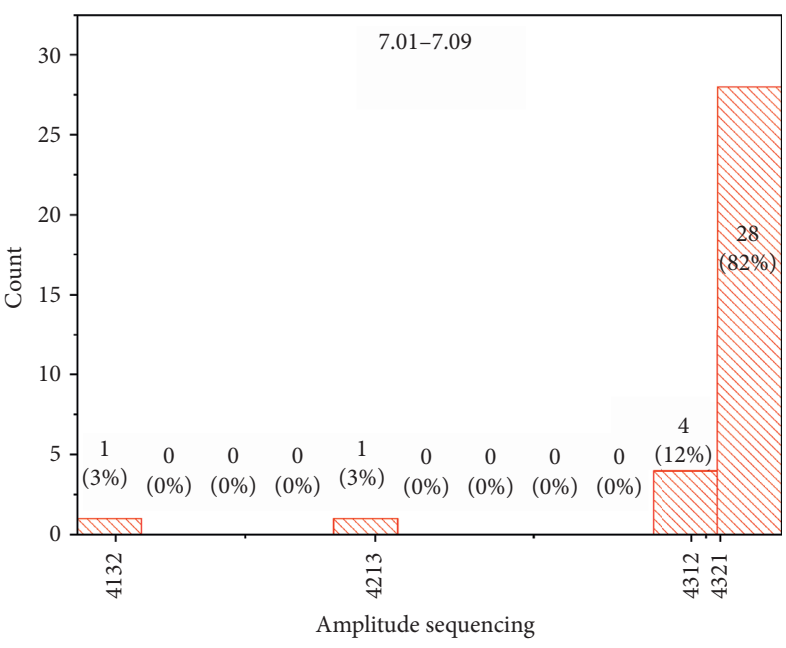

(d)

FIgURE 9: Statistical results of the proportion of amplitude sequencing in different periods. 


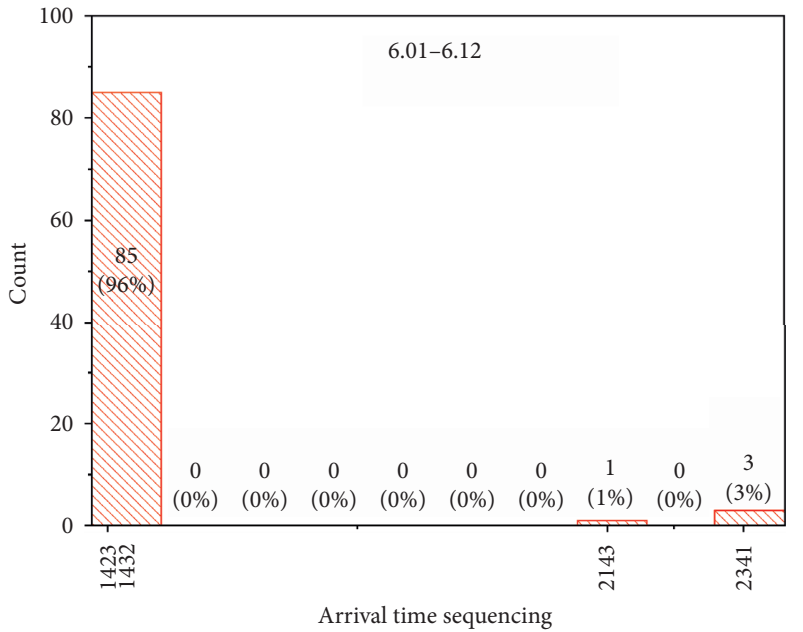

(a)

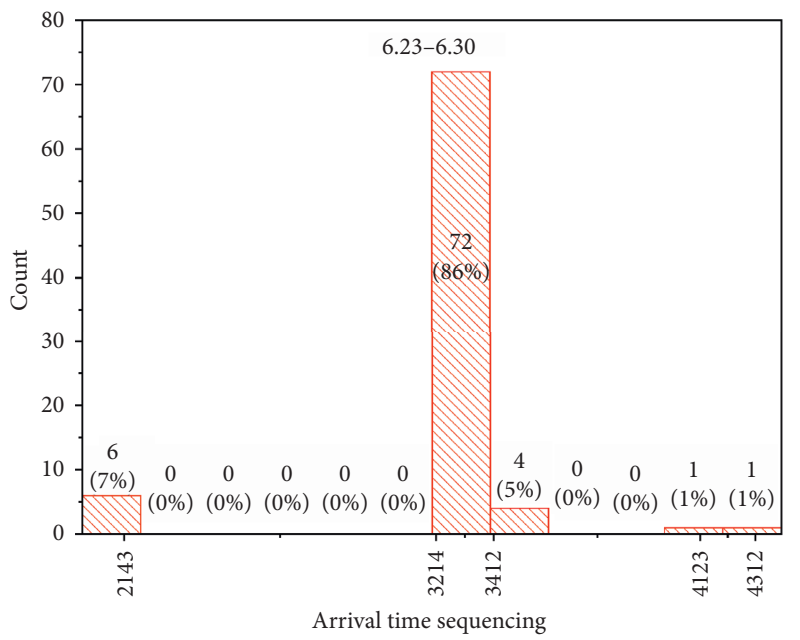

(c)

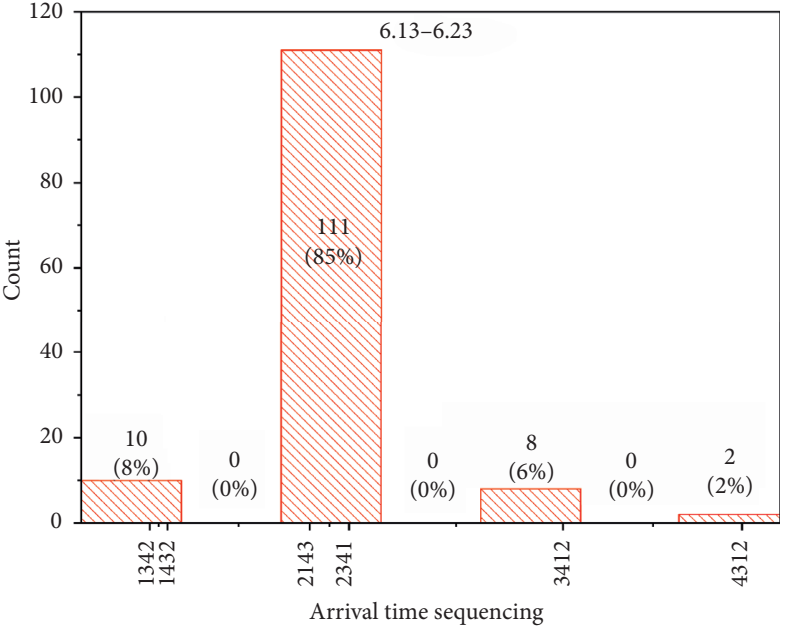

(b)

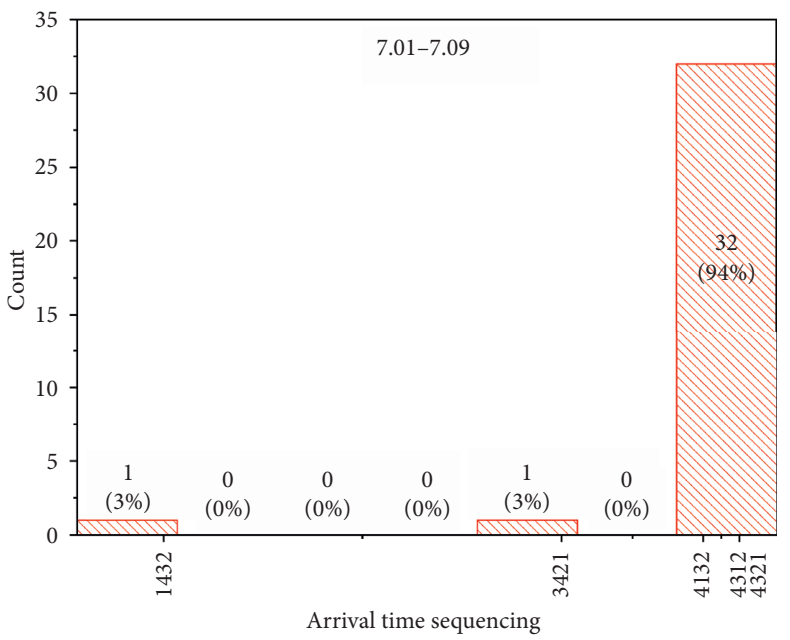

(d)

FIGURE 10: Statistical results of the proportion of arrival time sequencing in different periods.

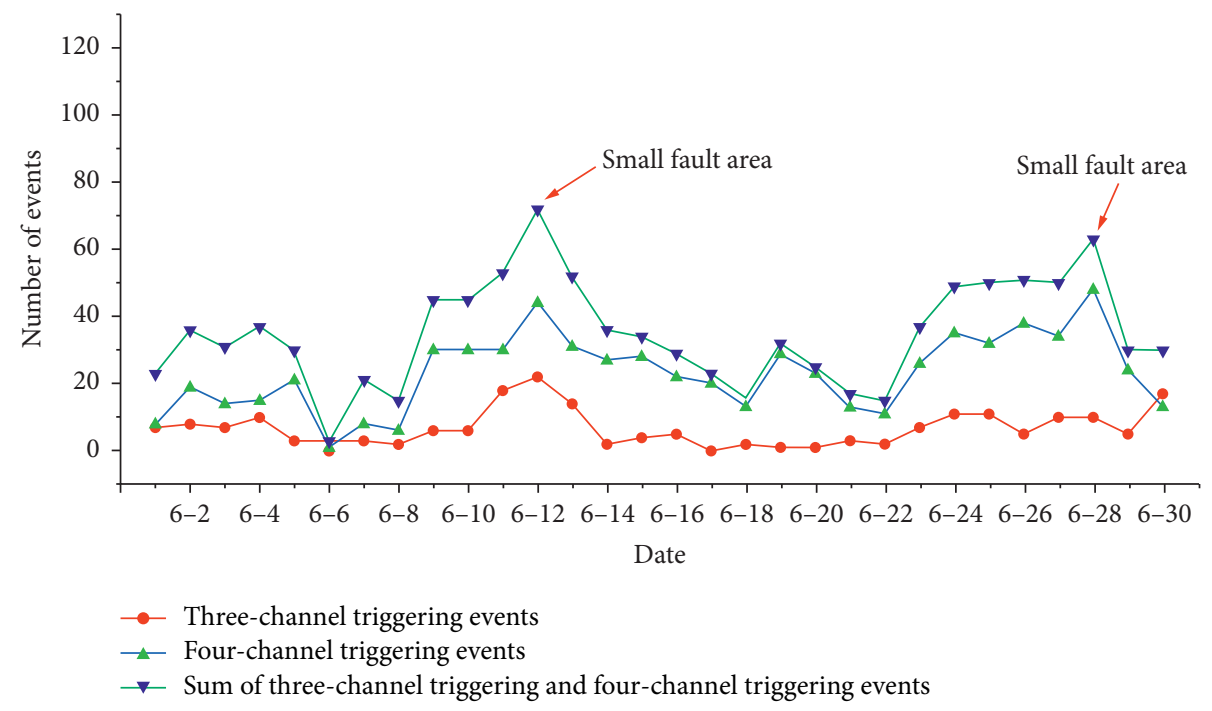

FIgURE 11: Relationship between the occurrence number of large MS events and fault areas. 
However, the geological structure is the place where rock burst occurs most frequently [51], which provides the possibility of using MS events as an indicator of rock burst monitoring and early warning in heading face.

In this study, the main characteristics of MS events in heading face are obtained through a set of running vibration signal acquisition system. However, the original intention of the system is not to test the vibration signal of heading face, and the setting of some parameters cannot be changed (the actual acquisition frequency of the acquisition instrument is increased to $10000 \mathrm{~Hz}$, the receiving frequency of the sensor is increased to $3000-5000 \mathrm{~Hz}$, and in this case, the sensor may need to adopt the form of the piezoelectric sensor), which leads to some unreasonable parts in the event characteristics we get, such as whether it exists in a higher main frequency distribution. However, if MS events can be used as monitoring indicators, the current system can fully meet the monitoring requirements. In addition, the relationship between the occurrence number of MS events and geological structure is obtained only on the basis of the data result of a specific location in a certain period of time, and whether it conforms to the law in other places and other time periods still needs further testing.

\section{Conclusion and Future Work}

In this paper, the basic characteristics of MS events which are different from $\mathrm{AE}$ events in heading face are obtained: maximum MA value is $10258 \mathrm{mV}$; minimum and maximum values of main frequency are $14 \mathrm{~Hz}$ and $515 \mathrm{~Hz}$, respectively; and maximum event duration is $1.78 \mathrm{~s}$. More importantly, the fact that more than $80 \%$ of MS events occurred near the heading face is got through amplitude sequencing and arrival time sequencing of sensors. The relationship between the occurrence number of MS events and geological structure and the risk of rock burst is discussed, which provides the possibility of using MS events as an indicator of rock burst monitoring and early warning in heading face. The results are of great significance for the study of mechanism of rock burst and the design of the vibration signal acquisition system in heading face of underground coal mine. For the future work, the sampling frequency of the acquisition instrument and the receiving frequency of the sensor should be increased to get the MS event parameters more accurately. In addition, more case verification work should be carried out.

\section{Data Availability}

The data used to support the findings of this study are available from the corresponding author upon request.

\section{Conflicts of Interest}

The authors declare that they have no conflicts of interest.

\section{Acknowledgments}

This research was funded by the Shandong Energy Group Co., LTD, grant no. 2019 SDZY02.

\section{References}

[1] L. Jiang, P. Kong, P. Zhang et al., "Dynamic analysis of the rock burst potential of a longwall panel intersecting with a fault," Rock Mechanics and Rock Engineering, vol. 53, 2019.

[2] G. C. Zhang, Z. J. Wen, S. J. Liang et al., "Ground response of a gob-side entry in a longwall panel extracting $17 \mathrm{~m}$-thick coal seam: a case study," Rock Mechanics and Rock Engineering, vol. 53, no. 2, pp. 497-516, 2019.

[3] G.-c. Zhang, Y.-l. Tan, S.-j. Liang, and H.-g. Jia, "Numerical estimation of suitable gob-side filling wall width in a highly gassy longwall mining panel," International Journal of Geomechanics, vol. 18, 2018.

[4] Z. Wancheng, N. Leilei, L. Shaohua, and L. Shuai, "Creepimpact test of rock: status-of-the-art and prospect," Journal of Mining and Strata Control Engineering, vol. 1, no. 1, 2019.

[5] S. Liu, X. Li, D. Wang, and D. Zhang, "Experimental study on temperature response of different ranks of coal to liquid nitrogen soaking," Natural Resources Research, vol. 30, 2020.

[6] C. Meifeng, "Key theories and technonogies for surrounding rock stability and ground control in deep mining," Journal of Mining and Strata Control Engineering, vol. 2, no. 3, 2020.

[7] Z. Guangchao, Z. Chuanwei, C. Miao, and T. Guangzhe, "Ground response of entries driven adjacent to a retreating longwall panel," International Journal of Rock Mechanics and Mining Sciences, vol. 138, 2021.

[8] L. Yao and D. Gang, "Reasonable width of narrow coal pillars in roadway driving with gas drainage hole," Journal of Mining and Strata Control Engineering, vol. 2, no. 1, 2020.

[9] X. Li, Z. Cao, and Y. Xu, "Characteristics and Trends of Coal Mine Safety Development," Energy Sources, Part A: Recovery, Utilization, and Environmental Effects, vol. 52, pp. 1-19, 2020.

[10] W. Zhang, N. Ma, J. Ma, C. Li, J. Ren, and B. Jiang, "Mechanism of rock burst revealed by numerical simulation and energy calculation," Shock and Vibration, vol. 2020, Article ID 8862849, 15 pages, 2020.

[11] Z. Xiufeng, Q. Xiaocheng, and W. Quande, "Development and application of multi-dimension multi-parameter monitoring and early warning platform of coal bursts," Journal of Mining and Strata Control Engineering, vol. 3, no. 01, pp. 69-78, 2021.

[12] W. Zhang, N. Ma, J. Ren, and C. Li, "Peak particle velocity of vibration events in underground coal mine and their caused stress increment," Measurement, vol. 169, 2021.

[13] X. Yongxue, J. Wenjun, S. Shijie et al., "Experimental study on hydraulic reaming of gutters in coal seam with impact pressure," Journal of Mining and Strata Control Engineering, vol. 2, no. 01, pp. 84-91, 2020.

[14] W. Zhang, C. Li, J. Ren, and Z. Wu, "Measurement and application of vibration signals during pressure relief hole construction using microseismic system," Measurement, vol. 158, 2020.

[15] W. Cai, L. Dou, M. Zhang, W. Cao, J.-Q. Shi, and L. Feng, "A fuzzy comprehensive evaluation methodology for rock burst forecasting using microseismic monitoring," Tunnelling and Underground Space Technology, vol. 80, pp. 232-245, 2018.

[16] C. Mark, "Coal bursts that occur during development: a rock mechanics enigma," International Journal of Mining Science and Technology, vol. 28, no. 1, pp. 35-42, 2018.

[17] B. Hebblewhite and J. Galvin, "A review of the geomechanics aspects of a double fatality coal burst at Austar Colliery in NSW, Australia in April 2014," International Journal of Mining Science and Technology, vol. 27, no. 1, pp. 3-7, 2017. 
[18] H. Zhen, Evolution Law of Plastic Zone and Burst Failure Mechanism of Gateway in Yima Coalfield, China University of mining and Technology, Beijing, China, 2018.

[19] X. Li, Z. Li, E. Wang et al., "Extraction of microseismic waveforms characteristics prior to rock burst using HilbertHuang transform," Measurement, vol. 91, pp. 101-113, 2016.

[20] J. Ning, J. Wang, L. Jiang, N. Jiang, X. Liu, and J. Jiang, "Fracture analysis of double-layer hard and thick roof and the controlling effect on strata behavior: a case study," Engineering Failure Analysis, vol. 81, pp. 117-134, 2017.

[21] C.-P. Lu, L.-M. Dou, N. Zhang et al., "Microseismic frequency-spectrum evolutionary rule of rockburst triggered by roof fall," International Journal of Rock Mechanics and Mining Sciences, vol. 64, pp. 6-16, 2013.

[22] W. Zhang, X. Qu, C. Li et al., "Fracture analysis of multi-hard roofs based on microseismic monitoring and control techniques for induced rock burst: a case study," Arabian Journal of Geosciences, vol. 12, p. 784, 2019.

[23] G. Yang, F. Jiang, X. Qu, L. Li, Q. Wei, and N. Li, "Comprehensive monitoring and early warning technology for rock burst of tunneling face with thick coal seams," Chinese Journal of Geotechnical Engineering, vol. 41, 2019.

[24] B. Li, Research on Evolution Mechanism and Prevention of Rock Burst in Deep Coal Seam Excavation Roadway, Shandong University of science and technology, Shandong, China, 2019.

[25] S. Zhu, F. Jiang, X. Wang, Y. Jiang, T. Ning, and S. Sun, "Energy accumulation characteristics and rockburst mechanism of surrounding rock at heading face of extra-thick coal seam," Chinese Journal of Geotechnical Engineering, vol. 41, 2019.

[26] C. Jianwei, "Analysis of roadheader's rotarytable on vibration modal based on finite element method and tested data," Journal of Mining and Strata Control Engineering, vol. 2, no. 2, 2020.

[27] J. Li, J. Yue, Y. Yang, X. Zhan, and L. Zhao, "Multi-Resolution Feature Fusion model for coal rock burst hazard recognition based on Acoustic Emission data," Measurement, vol. 100, pp. 329-336, 2017.

[28] J. Xie, J. Xu, and F. Wang, "Mining-induced stress distribution of the working face in a kilometer-deep coal mine-a case study in Tangshan coal mine," Journal of Geophysics and Engineering, vol. 15, no. 5, pp. 2060-2070, 2018.

[29] X. Li, E. Wang, Z. Li, Z. Liu, D. Song, and L. Qiu, "Rock burst monitoring by integrated microseismic and electromagnetic radiation methods," Rock Mechanics and Rock Engineering, vol. 49, no. 11, pp. 4393-4406, 2016.

[30] J. Xu, E. Wang, and R. Zhou, "Real-time measuring and warning of surrounding rock dynamic deformation and failure in deep roadway based on machine vision method," Measurement, vol. 149, 2020.

[31] M. Liang and X. Fang, "Application of fiber bragg grating sensing technology for bolt force status monitoring in roadways," Applied Sciences, vol. 8, 2018.

[32] G. Song, W. Li, B. Wang, and S. C. Ho, "A review of rock bolt monitoring using smart sensors," Sensors (Basel), vol. 17, 2017.

[33] G. Manthei and K. Plenkers, "Review on in situ acoustic emission monitoring in the context of structural health monitoring in mines," Applied Sciences, vol. 8, 2018.

[34] L. Dong, D. Sun, X. Li, and K. Du, "Theoretical and experimental studies of localization methodology for $\mathrm{AE}$ and microseismic sources without pre-measured wave velocity in mines," IEEE Access, vol. 5, pp. 16818-16828, 2017.
[35] S. Zhu, F. Jiang, J. Liu et al., "Mechanism and monitoring and early warning technology of rock burst in the heading face of compound thick coal seam," Journal of China Coal Society, vol. 45 , pp. $1659-1670,2020$.

[36] X. Lai, J. Ren, F. Cui et al., "Study on vertical cross loading fracture of coal mass through hole based on AE-TF characteristics," Applied Acoustics, vol. 166, 2020.

[37] C.-P. Lu, Y. Liu, H.-Y. Wang, and P.-F. Liu, "Microseismic signals of double-layer hard and thick igneous strata separation and fracturing," International Journal of Coal Geology, vol. 160-161, pp. 28-41, 2016.

[38] P. Wang, L. Jiang, J. Jiang, P. Zheng, and W. Li, "Strata behaviors and rock burst-inducing mechanism under the coupling effect of a hard, thick stratum and a normal fault," International Journal of Geomechanics, vol. 18, 2018.

[39] M. Bukowska, "The rockbursts in the upper silesian coal basin in Poland," Journal of Mining Science, vol. 48, 2012.

[40] C.-P. Lu, G.-J. Liu, Y. Liu, N. Zhang, J.-H. Xue, and L. Zhang, "Microseismic multi-parameter characteristics of rockburst hazard induced by hard roof fall and high stress concentration," International Journal of Rock Mechanics and Mining Sciences, vol. 76, pp. 18-32, 2015.

[41] A.-y. Cao, L.-m. Dou, C.-b. Wang, X.-x. Yao, J.-y. Dong, and Y. Gu, "Microseismic precursory characteristics of rock burst hazard in mining areas near a large residual coal pillar: a case study from xuzhuang coal mine, xuzhou, China," Rock Mechanics and Rock Engineering, vol. 49, no. 11, pp. 4407-4422, 2016.

[42] J. Feng, E. Wang, H. Ding, Q. Huang, and X. Chen, "Deterministic seismic hazard assessment of coal fractures in underground coal mine: a case study," Soil Dynamics and Earthquake Engineering, vol. 129, 2020.

[43] J. Kong, Wu Jiang, and N. Chen, "Numerical analysis of roadway rock-burst hazard under superposed dynamic and static loads," Energies, vol. 12, 2019.

[44] X. Ding, X.-C. Xiao, D. Wu, and X.-F. Lv, "Mechanical properties and charge signal characteristics in coal material failure under different loading paths," International Journal of Coal Science \& Technology, vol. 6, no. 1, pp. 138-149, 2019.

[45] L. Dou, K. Yang, and X. Chi, "Fracture behavior and acoustic emission characteristics of sandstone samples with inclined precracks," International Journal of Coal Science \& Technology, vol. 8, 2020.

[46] K. Holub, J. Holečko, J. Rušajová, and A. Dombková, “Longterm development of seismic monitoring networks in the OSTRAVA-karviná coal mine district," Acta Geodyn, vol. 9, pp. 115-132, 2012.

[47] J. Wang, B. Hu, W. Li, G. Song, L. Jiang, and T. Liu, "Design and application of fiber Bragg grating (FBG) geophone for higher sensitivity and wider frequency range," Measurement, vol. 79, pp. 228-235, 2016.

[48] D. Chicco, "Siamese neural networks: an overview," Methods in Molecular Biology, vol. 2190, pp. 73-94, 2021.

[49] J. Liu, M. Yang, D. Wang, and J. Zhang, "Different bedding loaded coal mechanics properties and acoustic emission," Environmental Earth Sciences, vol. 77, 2018.

[50] H. Yang, G. Wen, Q. Hu, Y. Li, and L. Dai, "Experimental investigation on influence factors of acoustic emission activity in coal failure process," Energies, vol. 11, 2018.

[51] S. Wang, W. Ju, J. Pan, and C. Lu, "Mechanism of energy partition evolution of excavation roadway rock burst in coal seam under tectonic stress field," Journal of China Coal Society, vol. 44, pp. 2000-2010, 2019. 